\title{
Memória e formalização social do passado nas organizações*
}

\author{
Alessandra de Sá Mello da Costa** \\ Luiz Alex Silva Saraiva***
}

SumáRIo: 1. Introdução; 2 . A memória, seu lugar nos estudos organizacionais e a história empresarial; 3. A apropriação dos materiais da memória pela história empresarial e a dicotomia monumento/documento; 4. Conclusões.

Summary: 1. Introduction; 2 . The memory, its place in organizational studies and business history; 3 . The appropriation of memory contents by business history and the dichotomy monument/document; 4 . Conclusions.

Palavras-chave: memória organizacional; história empresarial; formalização social do passado.

KEY WORDs: organizational memory; business history; past social formalization.

O objetivo deste artigo é iniciar uma discussão crítica acerca da memória e seu lugar nos estudos organizacionais, mais especificamente no que diz respeito à história empresarial. Pensar o tema memória permite refletir sobre a ideia de que nenhum diálogo acerca do passado e do presente é neutro, uma vez que exprime um sistema de atribuições de valores. Isto significa que a memória torna possível uma (re)elaboração do mundo, transformando e sustentando realidades existentes, e é nesse sentido que, como sustenta Ricoeur (2007), tanto o excesso quanto a escas-

\footnotetext{
* Artigo recebido em jun. 2010 e aceito em maio 2011.

** Professora do Departamento de Administração da Pontifícia Universidade Católica do Rio de Janeiro (IAG/PUC/RJ). Doutora em administração pela Escola Brasileira de Administração Pública e de Empresas da Fundação Getulio Vargas (Ebape/FGV). Endereço: PUC, rua Marquês de São Vicente, 225 - Gávea — CEP 22451-900, Rio de Janeiro, RJ, Brasil. E-mail: Alessandra. costa@iag.puc-rio.br.

*** Professor adjunto do Departamento de Ciências Administrativas e do Centro de Pós-Graduação e Pesquisas em Administração da Faculdade de Ciências Econômicas da Universidade Federal de Minas Gerais (Cepead/Face/UFMG). Doutor e mestre em administração pela UFMG. Bacharel em administração pela Universidade Federal de Sergipe (UFS). Endereço: Universidade Federal de Minas Gerais, Faculdade de Ciências Econômicas, av. Antonio Carlos, 6627 - Pampulha - CEP 31270-901, Belo Horizonte, MG, Brasil. E-mail: saraiva@face.ufmg.br.
} 
sez de memória (e o interesse por ela) representam algo. Discutir a apropriação da memória pelas empresas significa resgatar a perspectiva histórica e problematizar a opção dos gestores das organizações a respeito do que lembrar - e do que esquecer. Não é neutro, assim, o resgate do passado empresarial: esse processo se submete a uma intenção maior e mais profunda do que a mera ilustração cronológica de acontecimentos anteriores. Diz respeito, em última instância, à legitimidade de alguns atores para definir, de forma unilateral, o que deve ser lembrado naquele contexto, endereçando aos estudos organizacionais a tarefa de ampliar a compreensão da dinâmica das organizações, permitindo aos que têm voz e pouco podem manifestá-la que contem outras histórias.

\section{Memory and past social formalization in organizations}

In this paper we deal with a critical discussion about memory and its place at organizational studies, more specifically in business history. To think about memory allows thinking the idea of any dialogue about past and present be neutral, once expresses a value attribute system. Memory makes possible a world (re)elaboration, changing and supporting existing realities. In this sense, as Ricoeur (2007) argue, the excess or lack of memory (and interest about it) represent something. To discuss memory appropriation by companies implies a rescue of a historical perspective and also a critics about managers' option about what to remember - and what to forget. It isn't neutral, thus, rescue of business past: this process follows a wider and deeper intention than just to illustrate chronologically past happenings. It refers to the legitimacy of some actors do define, unilaterally, what must be remembered in that context, directing to organizational studies the job of widening the comprehension of organizational dynamics, allowing the telling of other histories by that ones who have voices and haven't shown them.

\section{Introdução}

O objetivo deste artigo é iniciar uma discussão crítica acerca da memória e seu lugar nos estudos organizacionais, mais especificamente no que diz respeito à história empresarial. Conceito amplamente difundido e debatido nas ciências humanas em geral, e na área de história, em particular, a memória apresentase como uma temática particularmente desafiadora no campo dos estudos organizacionais. A dimensão do desafio se conecta ao fato de que, em uma área que pretende aprofundar o que jaz sob o funcionamento da administração, a discussão da memória ocorre dentro de uma perspectiva de memória social e coletiva, algo ainda pouco levado a cabo. Como não há apenas uma memória, é preciso resgatar outros registros quase inexistentes, silenciosos, não óbvios, mas, também, legítimos. 
Neste texto, não se vincula diretamente o conceito de memória à ideia de conhecimento, e tampouco à de conhecimento organizacional. Memória, de uma forma mais abrangente, é entendida como a condição daquilo que se tem no presente e que pertence ao passado. Segundo Pollak $(1989,1992)$, a memória é um fenômeno construído socialmente e são duas as suas funções essenciais: manter a coesão interna e defender as fronteiras daquilo que um grupo tem em comum. Em função dessas condições, transforma-se tanto em um quadro de referência quanto em pontos de referência por meio da identificação e do compartilhamento de significados, ou seja, em "uma memória estruturada com suas hierarquias e classificações, uma memória [...] que, ao definir o que é comum a um grupo e o que o diferencia dos outros, fundamenta e reforça os sentimentos de pertencimento e as fronteiras socioculturais" (Pollak, 1989:3). No entanto, o processo de criação e formalização desses pontos de referência não ocorre sem disputas políticas e pode adquirir um caráter destruidor, uniformizador e opressor.

Pensar o tema memória permite refletir sobre a ideia de que nenhum diálogo acerca do passado e do presente é neutro, uma vez que exprime um sistema de atribuições de valores. A memória pode ser compreendida como uma condição modificadora, uma vez que vincula o conhecimento do passado com as perspectivas. Isto significa que a memória, quando formalizada, torna possível uma (re)elaboração do mundo, transformando e sustentando realidades existentes. É nesse sentido que, como sustenta Ricoeur (2007), tanto o excesso quanto a escassez de memória (e o interesse pela memória) são representativos de alguma coisa. Assim, pode-se argumentar que existe uma interação entre passado e presente que atribui relevância a uma função social do passado onde são recolhidos, classificados e agrupados fatos em razão das necessidades do presente.

Por outro caminho, pode-se argumentar que os estudos sobre memória organizacional (organizational memory studies) têm se limitado apenas a visões gerencialistas, que privilegiam a função utilitária da memória no processo de tomada de decisão empresarial por meio da elaboração de modelos mecânicos processados em sistemas de informação (como o modelo de memória organizacional de James Walsh e Gerardo Ungson), deixando à margem das discussões temas vinculados aos estudos de memória social, como a memória coletiva, a memória cultural, as comemorações ou rememorações sociais (Rowlinson et al., 2010).

A carência de trabalhos nos estudos organizacionais sobre o tema pode ser percebida como algo sintomático: em uma área na qual a proximidade do mercado leva à supervalorização do hoje, e do agora, do imediatismo dos 
resultados em detrimento do longo prazo, da adoção sem questionamentos de modelos já prontos, principalmente estrangeiros, um olhar mais crítico e cuidadoso ao passado pode ser um perigo. Isto é, pode ser potencialmente revelador da institucionalização de processos e de valores que desvelam relações de poder e de dominação que, eventualmente, escapam em uma análise mais superficial.

Discutir a apropriação da memória pelas empresas como pauta dos estudos organizacionais significa, entre outras coisas, resgatar a perspectiva histórica e problematizar a opção dos gestores das organizações a respeito do que lembrar - e do que esquecer. Trata-se aqui dos usos e abusos aos quais se presta a memória enquanto atividade exercida — prática — com intenção de representar em verdade as coisas passadas (Ricoeur, 2007). Essa intencionalidade atribuída às formas de representação do passado não pode ser desvinculada das relações de poder inerentes a esse "resgate". Ou seja: quem constrói a memória? Com que finalidade? Para quem? Em detrimento de quem?

Segundo Le Goff (1992), o que sobrevive não é o conjunto daquilo que existiu no passado, mas o resultado de escolhas. Escolhas do pesquisador que seleciona suas fontes, priorizando determinados documentos (e negligenciando outros), extraindo do conjunto dos dados do passado e atribuindo-lhe por meio de sua intervenção um valor de testemunho. Dessa forma, não existe documento inocente ou neutro, sendo esse "o resultado de uma montagem da história, da época, da sociedade que o produziram, mas também das épocas sucessivas durante as quais continuou a viver, talvez esquecido, durante as quais continuou a ser manipulado, ainda que pelo silêncio" (Le Goff, 1992:538).

Todas essas ideias, intencionalidades, discussões e silêncios podem ser transpostos sem dificuldade para o mundo das empresas, onde a memória organizacional é recorrentemente construída, reconstruída e disseminada em suas estruturas. Isso significa que se assiste a um significativo embate simbólico nas organizações no que diz respeito ao passado, o que acontece não apenas porque a memória humana falha ao procurar reconstituí-lo, já que cognitivamente atuam filtros que relativizam experiências e preservam determinadas lembranças, mas, também, em virtude de o passado que se conta e a história que se dissemina serem, deliberadamente, objetos de uma intencionalidade organizacional.

Tal intencionalidade está presente no dia a dia da organização e pode ser identificada nas várias expressões da memória coletiva da empresa, por exemplo, em seus sistemas de informações, em sua arquitetura, em suas orientações estratégicas, em seus procedimentos de operação padronizados (Walsh 
e Ungson, 1991), e, no caso particular deste artigo, na narrativa de sua história. Assim, o papel da memória e da história organizacional pode ser mais bem entendido quando inserido em um embate no nível da busca por legitimidade, já que da mesma forma que os gestores das empresas consideram legítimo haver uma versão unilateral da história, uma vez que são proprietários dos recursos materiais, da estrutura, no sentido marxiano, os trabalhadores, por exemplo, consideram legítima a reinterpretação do que se conta, o que multiplica as perspectivas existentes, ampliando as possibilidades de análise e de simbolização do cotidiano organizacional (Martin, 1992).

Essa pluralidade, que existe de fato nas organizações, contudo, não resiste ao longo do tempo - pelo menos não do ponto de vista formal —, prevalecendo uma dada visão do passado que se torna hegemônica, sempre contada por alguém, aparentemente sem nenhum outro propósito além de retratar as coisas tal como elas eram. Questiona-se aqui, entretanto, essa altruísta, "desinteressada" e ideologizada versão oficial da história. A história também é, ela própria, uma versão do passado, conforme discute De Decca (2004). Isto é, a história não é uma ciência do passado, mas, ao contrário, é a ciência dos homens no tempo (Bloch, 2001), cuja relevância reside na importância atribuída ao presente para a compreensão do passado: a historiografia elege temas que falam mais de suas próprias inquietações e convicções do que de tempos memoráveis (Schwarcz, 2001).

Segundo Costa, Barros e Martins (2009), a partir dos anos 1940, a historiografia da história nova promove um profundo questionamento tanto da noção de fato histórico, não mais um objeto dado e acabado, uma vez que é resultado da construção do historiador, quanto da noção de documento, que se amplia, não sendo ele mais considerado algo objetivo e inocente. Tal abordagem postula que a própria ausência de documentos passa a ser significativa, pois elucida que esses são sempre produtos de uma sociedade que os fabricou conforme relações de forças e de poder. Isso implica haver embates e disputas simbólicas silenciosas, algumas vezes explícitas, sobre o direito de dispor de prerrogativas ao relatar o que se foi.

Nesse sentido, a impossibilidade humana de reconstituir as coisas precisamente como eram leva a que se desenvolvam versões, relatos necessariamente plurais diante de uma realidade que é polifônica em sua origem e, também, em seu destino. Isso relativiza a noção de que é fato o passado formalmente descrito pelas organizações; esse não passa de uma versão, ainda que legitimada pela posse de recursos - o que absolutamente não invalida outras possibilidades de descrever o passado, também legítimas. Essa crítica a uma versão unívoca de fato histórico permite aos pesquisadores o reconhe- 
cimento de outras realidades (intencionalmente ou não) negligenciadas. Mas, até que ponto nas organizações são possíveis outras memórias além das formalmente legitimadas?

Para analisar tais elementos, além desta introdução, este artigo apresenta mais três seções. Na primeira, discute-se a memória e seu lugar nos estudos organizacionais por meio da história empresarial. Essa seção é sucedida por considerações sobre as apropriações dos materiais da memória por meio do resgate da dicotomia monumento/documento, o que permite a inserção de temas como objetividade e manipulação do passado, o passado social formalizado e o documento como instrumento de poder, o que precede as conclusões.

\section{A memória, seu lugar nos estudos organizacionais e a história empresarial}

Uma das formas possíveis de teorização acerca da apropriação da memória nos estudos organizacionais pode ser por meio da análise da história empresarial inserida na dicotomia monumento/documento. Ao contrário do que pregam os funcionalistas pragmáticos, a teorização, por si só, é um processo indispensável à compreensão da realidade. À medida que o indivíduo é capaz da abstração, com isso fugindo da mera esfera da aplicação de ideias, se liberta das limitações da concretude, evoluindo rumo a perspectivas focadas em elementos mais complexos. A teorização permite um reposicionamento no mundo em que se vive, fornecendo a oportunidade de não apenas procurar conceituá-lo, mas de, por meio desse conceito, estabelecer visões sobre o objeto observado. Há, assim, um caráter intrinsecamente emancipador que a teorização possui, já que, à medida que teorizam, os indivíduos encaram a realidade à sua maneira, fortalecendo o olhar localizado e os aspectos a ele relacionados (Burrell, 1998).

No que diz respeito especificamente à teorização organizacional, conforme salienta Reed (1998), essa discussão assume feições um tanto quanto complexas. A complexidade se deve, sobretudo, ao fato de que não se trata apenas de elaborar teorias sobre o mundo organizacional, mas considerar que há um caráter inevitavelmente ideológico sub-reptício a qualquer iniciativa de teorização. Isso significa que além da implícita noção de contribuição para a compreensão de elementos organizacionais e suas relações, quando se teoriza se participa, de uma forma mais ou menos ativa, de um embate político que possivelmente antecede os teorizadores e provavelmente lhes sucederá (Carrieri e Luz, 1998). 
Isto implica uma realidade que é construída socialmente por aqueles que "têm direito" e, principalmente, por aqueles que "podem se manifestar". Os que dominam a linguagem, os que a legitimam ou os que a podem divulgar exercem poder sobre os demais. A produção de teoria organizacional, portanto, é imbuída de um viés ideológico. Esse comprometimento na origem implica, de uma forma ou de outra, já a partir da produção, o argumento de autoridade, no sentido colocado por Demo (1995).

No mundo empresarial, a visão que se tem da teoria é bem menos ampla. Em linhas gerais, como apontado por vários autores, como Burrell (1998) e Reed (1998), nesse contexto deliberadamente se busca menos explicação do que aplicação. O exercício analítico, assim, é estreitamente dirigido pela necessidade empírica de solução de problemas, o que faz com que haja uma redução considerável das possibilidades de tornar plural essa análise. Com isso, as alternativas plurais de leitura do que se passa na organização se convertem em soluções simplificadas, ajustadas apenas ao que faz sentido do ponto de vista estratégico. A pluralidade da teorização organizacional anteriormente aludida, assim, se estreita em prol das necessidades mais imediatas das práticas. Se isso se dá no nível das operações propriamente ditas, o caso é ainda mais dramático quando entra em cena a história empresarial: sem compromisso com elaborações mais consistentes, predomina nas empresas uma preocupação com o relato de acontecimentos passados que põe em segundo plano a contribuição teórica - ou mesmo os fatos "tal como ocorreram".

De acordo com Gourvish (2006), é inegável o foco instrumental das empresas. Isso é particularmente evidente pela lógica de curto prazo e pela ótica comprometida com o futuro. É só porque o presente pode conter elementos que mantenham ou ampliem vantagens competitivas atuais que uma perspectiva histórica é adotada. Focos tradicionais empresariais, como conseguir maior confiança do mercado, levar a cabo ações de relações públicas que melhorem a imagem da empresa, ou que proporcionem a adoção de modelos bem-sucedidos no passado, são alguns dos objetivos da história empresarial. Essa noção de história é dirigida pela preocupação com a geração de valor para o acionista e, pelos aspectos mencionados, apresenta o risco de gerar um processo de "amnésia corporativa" em virtude de a versão que se deseja conservar ser comprometida com um foco específico, de melhoria do desempenho, o que pode resultar em repetições inócuas de receitas do passado.

A história empresarial insere-se na área maior da história dos negócios (business history), é a abordagem mais antiga que expressa a aproximação entre administração e história: o estudo sistemático de firmas individuais com base em sua própria documentação (Booth e Rowlinson, 2006). Seu desenvol- 
vimento não ocorreu de forma homogênea e sem rupturas e tem sua origem na aproximação entre a história dos negócios e a teoria econômica. Como atividade acadêmica, a história dos negócios se desenvolveu como uma ramificação da história econômica. Segundo Lobo (1997), apesar de os historiadores da atividade empresarial considerarem como precursores de sua área Jean Baptiste Say, Joseph Schumpeter e Henri Pirenne, a história empresarial começou a ser desenvolvida nos Estados Unidos com a formação, em 1926, da Business History Society e com o lançamento do Journal of Economic Business History, em 1928. Seu foco era o estudo isolado de empresas, sem integrá-las num contexto socioeconômico mais amplo.

Com uma perspectiva um pouco diferente, foi fundado em 1944 o Centro de História Empresarial na Universidade de Harvard com o foco em história social. Talcolt Parsons, por exemplo, foi um pesquisador influente na formação teórica desse centro, priorizando em suas pesquisas a capacidade gerencial e o prestígio social "de acordo com o reconhecimento pela sociedade da importância dos status ocupados pelos indivíduos" (Lobo, 1997:218). Na França e na Inglaterra, a história dos negócios adquire relevância apenas na década de 1950, mas também em uma perspectiva social. No Brasil, inicialmente, a produção sobre história empresarial era uma pesquisa sem perspectiva geral, apenas com o foco na administração interna de determinada unidade de produção ou na exaltação do fundador da empresa.

Verifica-se, nesse sentido, o relato de histórias empresariais que tendem a engrandecer os feitos do passado, a narrar de forma épica as dificuldades dos anos iniciais, a romantizar a atuação dos líderes em períodos-chave, enfim, a contar a história da empresa como se fosse um relato oficial e único de fatos - e não de uma versão, entre as várias possíveis (Leblebici e Shah, 2004). Ou seja, são narrativas acerca de negócios individuais, quase sempre comissionados pelas próprias companhias pesquisadas (Booth e Rowlinson, 2006), que podem ser utilizadas pelas empresas para fortalecer os vínculos: com seus funcionários e fornecedores - por meio de uma "história de vida corporativa" que expressa solidez, segurança financeira e princípios éticos; e com seus consumidores - por meio de um histórico de preocupação com o meio ambiente (Costa, Barros e Martins, 2009).

Como corrente teórica, a história de negócios só se amplia a partir da década de 1970, adquirindo características e linhas de pesquisa específicas. De acordo com Lobo (1997), por um lado, os pesquisadores brasileiros passam a focalizar o contexto socioeconômico; por outro, cresceram as pesquisas de estudos de casos procurando: a) entender as estratégias dos empresários; b) questionar visões já consagradas pela historiografia sobre as origens da indús- 
tria; c) compreender o papel dos empresários; d) observar as ações do Estado; e) analisar seus respectivos órgãos de classe.

De acordo com Harvey e Wilson (2007), atualmente a área de história dos negócios vem adquirindo cada vez mais relevância, em particular após a criação, principalmente na Europa, de ativas associações profissionais de historiadores de negócios que realizam encontros anuais, como a Association of Business Historians (ABH) e a European Business History Association (EBHA). Com relação às perspectivas que orientam as pesquisas, os trabalhos empíricos sobre empresas isoladas com foco na administração interna diminuíram. Em seu lugar, na Inglaterra e nos Estados Unidos, desenvolveu-se a história comparada de empresas, e, na França, a história empresarial numa perspectiva mais global. Essa ruptura, proveniente dos desdobramentos mais atuais da história dos negócios, fez com que os pesquisadores direcionassem seu foco tanto para as intercessões e conjunções da análise histórica quanto para o estudo de formas particulares de organização e processos, redefinindo o campo de estudo como humanístico e científico ao mesmo tempo.

De qualquer forma, discute-se neste artigo que a história empresarial apresenta-se como uma abordagem que, via de regra, com o argumento de arregimentar informações sobre o passado, se apresenta de forma pouco crítica, despolitizando a dinâmica organizacional ao longo do tempo e manipulando a memória de forma a construir um passado pretendido. Sobre a questão da história versus a história de negócios, Maielli (2006:342) abre algumas possibilidades para a compreensão da história na área empresarial:

por definição, conhecimento histórico é baseado em uma análise ex-post do passado. A história, como campo de conhecimento, contribui para a identidade sociocultural das organizações, estruturas e instituições, e ajuda a explicar a origem da forma presente. O conhecimento [histórico] dos negócios, por sua vez, deveria proporcionar aos gerentes tomar decisões no presente que afetarão o futuro dos negócios da organização.

A busca da historicidade do espaço organizacional se reflete na busca pela existência de um contexto específico para todos os acontecimentos e todos os fenômenos. Assumindo que o que é oficialmente definido como passado - o passado social formalizado - "é e deve ser claramente uma seleção particular da infinidade daquilo que é lembrado ou capaz de ser lembrado" (Hobsbawm, 2007:22), tornam-se fundamentais as tentativas de identificação de quais aspectos desse passado foram ou serão selecionados. É nesse contexto que a discussão acerca da apropriação da memória adquire relevância, e é com 
base nesses argumentos que se assume a ideia de que a dicotomia documento/monumento pode ser um veículo adequado para o questionamento dessa "exatidão" da história empresarial.

\section{A apropriação dos materiais da memória pela história empresarial e a dicotomia monumento/documento}

Os materiais da memória escolhidos podem se apresentar em duas formas principais: os monumentos, relacionados a heranças do passado, e os documentos, material à escolha do pesquisador. $\mathrm{O}$ monumento é o que evoca $\mathrm{o}$ passado e mantém a recordação, e vincula-se ao poder de perpetuação das sociedades históricas (voluntária ou involuntariamente), sendo um legado à memória coletiva.

O documento, ainda que resulte da escolha, de uma decisão do pesquisador, apresenta-se como uma prova histórica. Segundo Janotti (2006), é na ocasião em que a história se afirma como disciplina acadêmica que são estabelecidos os parâmetros metodológicos científicos rígidos com relação às fontes históricas, priorizando investigações sobre a importância da autenticidade documental. Por meio desse processo, o documento autêntico adquire o fundamento do fato histórico e, com base nessa suposição, pesquisadores afirmam que não existe notícia histórica sem documentos e que, se dos fatos históricos não foram registrados documentos (gravados ou escritos), tais fatos se perderam (Lefebvre, 1981). Isto é, ambos se fundem em um só fenômeno e a habilidade do pesquisador consiste exatamente em extrair dos documentos tudo o que eles contêm e em não lhes acrescentar nada do que eles não contêm: a memória se materializa na forma do documento.

No entanto, como o documento é fruto de um processo de seleção, as relações de poder que permeiam as escolhas terminam por transformar o documento em monumento. Dito de outra maneira, pode-se afirmar que todo documento é monumento, e que o que efetiva essa relação é sua utilização pelo poder. Assim, não existe um documento objetivo, inócuo, primário: "O documento não é qualquer coisa que fica por conta do passado, é um produto da sociedade que o fabricou segundo as relações de forças que aí detinham o poder [...] no limite, não existe documento verdade" (Le Goff, 1992:536). Daí a ideia de resgatar objetivamente o passado não passar de um desejo de alguns historiadores que tentam anular sua subjetividade ao buscar construir uma história "neutra", portanto, sem o viés próprio dos seres humanos que se 
voltam ao passado. Sendo, a rigor, um produto dos homens, a história se sujeita às limitações que os homens possuem, entre as quais se destaca o poder.

Essa relação dicotômica leva a um necessário, e recorrente, processo de crítica do documento - qualquer que ele seja - como monumento. Como todo documento é ao mesmo tempo verdadeiro e falso em função dos argumentos anteriormente apresentados, trata-se de pôr em evidência as condições de produção desse documento, e indicar em que medida o documento é ou não um instrumento de poder (Le Goff, 1992), o que pode ser um caminho bastante esclarecedor para se pensar de forma mais crítica o lugar da memória documentada na administração. Nada há de objetivo ou neutro em qualquer coisa produzida pelos homens, principalmente sua memória. Técnica e politicamente, essa é uma impossibilidade, que não pode ser tomada como algo pouco relevante nos estudos organizacionais.

Todo documento transformado em monumento é, ao mesmo tempo, verdadeiro e falso. Essa duplicidade de sentido pode ser mais bem compreendida quando se relativiza a objetividade do fato e do trabalho histórico, e concordase com Paul Valéry quando este diz que "a história é o produto mais perigoso que a química intelectual do intelecto elaborou [...] a história justifica o que quiser" (Valéry apud Le Goff, 1992:32). Para Pollak (1992:8), "se a memória é socialmente construída, é obvio que toda documentação também o é". A partir dessa afirmação, cabe o questionamento acerca do compromisso dos que buscam construir a história das empresas com os fatos. Não é incomum que se apresentem como fatos acontecimentos "ajustados", já que se deseja narrar a situação a partir de determinado ângulo. Nesse sentido, discute-se sobre o que realmente aconteceu no passado das empresas, ao contrário de se tomar como fato o que é apresentado como a única versão de sua história.

Em relação às condições de produção dos documentos, podem-se destacar duas problemáticas. Um primeiro ponto diz respeito ao compromisso do pesquisador organizacional com a versão "ajustada" dos fatos e não com os fatos históricos. Ao assumir esse encaminhamento para a pesquisa, os procedimentos metodológicos, essenciais à elaboração de conhecimento válido, ficam comprometidos e em segundo plano. Como Amatori (2009:) propõe, é necessário à história empresarial "um mínimo de fundamentos (ou informação)", o que pode ser questionado em várias narrativas empresariais.

Outro ponto refere-se ao uso de fontes secundárias. O material utilizado para conferir veracidade às histórias empresariais, coletado à época em que os acontecimentos se passaram, guardava relações com objetivos daquele período específico, e apenas a "leitura" interessada é que o faz dizer mais do que originalmente se propunha. As fontes tradicionais dessa área consistem 
em cartas, memorandos, periódicos e contas em geral. Ou seja, documentos referentes à formação da empresa; às deliberações de seus conselhos, departamentos e direção geral; ao seu patrimônio, suprimentos, estoques, produção, serviço financeiro, contabilidade, correspondência, jurisprudência, pessoal, serviços de estudos e comerciais (Costa, Barros e Martins, 2009).

Esse procedimento se relaciona diretamente com a questão da oficialidade dos registros. Por um lado, como chama a atenção Lobo (1997:220), grande parte das empresas não conserva de forma adequada seus documentos, sendo "muito comum [...] destruírem os documentos mais antigos ou deixarem-nos sem qualquer critério de classificação, acumulados em depósitos". Por outro lado, o uso de documentos da empresa, de quem se espera registro formalizado dos acontecimentos do passado, normalmente se dá em detrimento de outros registros, como os dos trabalhadores e de suas organizações, por exemplo, o que reforça a ideia de passado univocamente reconstituído.

A questão da oficialidade dos registros também assume importância quando o passado empresarial é rememorado por meio de documentos mais vinculados à publicidade, tais como: relatórios anuais, press releases, sítios na internet, revistas corporativas, entre outros. Por último, de forma complementar, as empresas, de acordo com Rowlinson e colaboradores (2010), se apropriam da memória social por meio de atrações que oferecem experiências de marca, comemorações corporativas de eventos nacionais e criação de museus corporativos, como são os casos do Hershey Foods Corporation's Chocolate World, do Bass Museum e do Henry Ford Museum Complex.

O documento transformado em monumento é um instrumento de poder. Segundo Pollak (1989:10), manter a coesão interna e defender as fronteiras daquilo que um grupo tem em comum implica, necessariamente, trabalhar com a ideia de memória enquadrada (e de trabalho de enquadramento da memória), que se alimenta do material fornecido pela história:

esse material pode sem dúvida ser interpretado e combinado a um sem-número de referências associadas; guiado pela preocupação não apenas de manter as fronteiras sociais, mas também de modificá-las, esse trabalho reinterpreta incessantemente o passado em função dos combates do presente e do futuro.

Tal trabalho de enquadramento, de forma a alcançar níveis aceitáveis de legitimidade e credibilidade, tem como seus principais agentes: os historiadores profissionais. Pollak (1989:10) argumenta que "o controle da memória se estende aqui à escolha de testemunhas autorizadas, ele é efetuado nas organizações mais formais pelo acesso dos pesquisadores aos arquivos". Assim, 
o que é historicamente legítimo, nesse sentido, se deve menos a fatos do que a versões politicamente comprometidas com as narrativas desses fatos. O que se chama de memória coletiva, assim, bem como a tradição que a sustenta, pode ser compreendido como o resultado de embates que endereçam aos grupos derrotados a tarefa de tomar como suas tradições que muitas vezes não lhes dizem respeito.

Le Goff (1992:477) alerta que "a memória, onde cresce a história, que por sua vez a alimenta, procura salvar o passado para servir o presente e o futuro. Devemos trabalhar de forma que a memória coletiva sirva para a libertação e não para a servidão dos homens". Até que ponto as organizações, ao produzir uma dada versão dos fatos passados, tratada como fato, não fazem disso um instrumento para submeter os trabalhadores, no nível ideológico, como alertam Pagès e colaboradores (1987)?

A servidão a que se refere Le Goff é notavelmente relacionada à noção de marginalidade histórica. Grupos marginais são excluídos historicamente por conta de processos sociais que conferem a uns grupos ascendência sobre outros, o que inclui a própria história. Como resultado, a injustiça social se perpetua por não serem explicitadas as particularidades desses grupos que, por não terem voz, cotidianamente suportam, de forma não voluntária, um registro social que não é seu (Schmitt, 1998:263).

No que tange à história empresarial, ainda que ela seja apresentada como unívoca e como resultado direto e objetivo do que foi oficialmente documentado ao longo de sua existência, ela abriga outras possibilidades de construção social do passado, nos termos de Berger e Luckmann (2005). Para ficar em apenas um exemplo: os trabalhadores e sua memória, fruto de vivência ao longo da existência da organização, são orientados por outros vetores, não sendo ilegítimas suas histórias, apenas silenciadas pelo discurso oficial. E isso não cabe na versão que interessa à empresa. Mas dar voz a esses indivíduos também precisa fazer parte da agenda dos estudos organizacionais.

\section{Conclusões}

O objetivo deste artigo é iniciar uma discussão crítica acerca da memória e seu lugar nos estudos organizacionais, mais especificamente no que diz respeito à história empresarial. Para isso foi construída uma argumentação em torno da análise das impossibilidades objetivas — e intencionalidades veladas - de as empresas resgatarem o passado tal como ele aconteceu, sendo eivadas de relações de poder as histórias das empresas. Em parte, como se argumentou, isso 
se deve a uma impossibilidade metodológica de os historiadores alcançarem e tratarem os registros históricos empresariais como fatos, uma vez que se comprometiam, no passado, com aspectos essencialmente funcionais, e muitos deles não escapam no presente. Por outro lado, há uma intenção deliberada de que esse passado pareça ser o mais objetivo e "limpo" possível, para que os fatos venham à tona tal como ocorreram.

Essas intenções, regidas pela procura da objetividade, terminam por compor uma história sem manchas, a rigor sem humanidade, pois esvaziam o sentido propriamente social dos relatos que procuram construir para lhes conferir características objetivas. As divergências, enganos, mentiras, entre outros aspectos típicos das construções humanas, são simplesmente silenciados por uma história que resgata uma memória que se pretende asséptica e idônea. Como outros atores organizacionais - por exemplo, os trabalhadores - normalmente não dispõem dos mesmos recursos das empresas para registrar esse passado, a versão principal, de oficial se converte em única, e de única, em inequívoca, de única forma possível do passado.

A referência ao passado, bem como a apropriação de interpretações acerca desse passado, torna possível a coesão e a definição dos respectivos papéis dos mais diferentes grupos e organizações que formam uma sociedade, como sindicatos, igrejas, famílias, nações e, no caso específico deste artigo, as empresas. Não é neutro o resgate do passado empresarial: esse processo se submete a uma intenção maior e mais profunda do que a mera ilustração cronológica de acontecimentos anteriores. Diz respeito, em última instância, à legitimidade que possuem os empresários e seus representantes de definir, unilateral e extensivamente, o que deve ser lembrado naquele contexto organizacional específico. $\mathrm{O}$ que esquecer também integra o mesmo passado, mas não interessa à reconstituição de uma história baseada em memórias "limpas" e objetivas.

O embate político envolvendo a memória (no sentido do que deve ser lembrado ou esquecido) adquire relevância uma vez que a (re)construção da memória - por ser um dos elementos identitários essenciais - é um instrumento de poder. Ou seja, permite desvelar o componente ideológico presente nas escolhas e a formação social do passado. Em outras palavras, os processos de esquecimento e de lembrança são intrinsecamente ligados. Só se esquece de algo que constituía parte do que se lembra e, como a memória humana é falha, só se lembra necessariamente esquecendo algo. Esses filtros de memória, se atendem a certa ideia de normalidade em um sistema social que admite a imperfeição, não correspondem aos equivalentes apresentados no universo das empresas. Ali está na base do movimento rumo ao resgate 
do passado uma seleção intencional do que lembrar, uma vez que não se separa do passado a ideologia que se deseja construir no presente. Nada há de acidental, assim, em memórias apagadas, em acontecimentos esquecidos na história das empresas.

O que se presencia é uma espécie de hierarquização das memórias. As mais bem classificadas são as que refletem o posicionamento ideológico da empresa, o que normalmente implica alinhamento com os valores enfatizados no presente, as memórias oficiais, em geral presentes na descrição do passado. A essas se opõem, em maior ou menor grau, as "outras" memórias, que, dependendo do teor, podem ser "memórias esquecidas", muitas vezes consideradas relativamente menos importantes, não cabendo serem lembradas; "memórias subterrâneas", oriundas de uma história não oficial, e, por isso, sussurradas; "memórias clandestinas", que supõem ilegitimidade do ponto de vista oficial, e por isso são combatidas pela versão oficial da história da empresa; "memórias silenciadas", sobre as quais pesa uma pressão para que não sejam sequer sussurradas, uma vez que preservam versões às quais não se deseja acesso; "memórias vergonhosas", que podem apresentar o resultado de decisões desastradas, que causaram embaraço aos gestores no período em que ocorreram; e "memórias proibidas", que constituem verdadeiros tabus, e cujo resgate não pode ser sequer cogitado. Reconhecer tais possibilidades de memória é pluralizar a história da empresa, que escolhe uma dada versão do passado, e que a incrementa a partir de uma dada memória - que é sempre uma das muitas disponíveis, concorrentes e complementares.

A esse respeito, Amatori (2009), um pesquisador da história de negócios, aponta elementos que se apresentam, no âmbito deste artigo, como muito adequados para uma crítica à construção desse passado. Para ele, a fim de que se consiga relatar de "forma responsável e com qualidade" as histórias empresariais, é preciso:

- apresentar independência, pois sem o "afastamento" ideológico necessário, corre-se o risco de se relatar apenas o que o empresariado e seus representantes desejam ouvir. Como é humanamente impossível proceder a tal afastamento, essa recomendação soa como uma tentativa de tornar objetivo e neutro algo que constitutivamente não o é;

v que os dados sejam relevantes, pois é preciso liberdade para a seleção de material relevante para a recomposição dos acontecimentos, e isso cabe ao pesquisador. Mas até que ponto isso é possível, uma vez que o selecionado para ser preservado está em arquivos sob controle dos empresários e seus 
representantes? Não seria uma grande ficção buscar dados relevantes sobre os quais não se tenha liberdade de seleção?;

v fazer uso de recursos amplos e críticos. Reforçando a ideia de objetividade, quanto mais variadas as fontes de dados, mais "objetiva" seria a história reconstituída da empresa, a fim de proporcionar possibilidades de reconstituição factíveis com o que se passou, de fato. $O$ não dito nesse caso é que o que se preserva, por mais variado que seja, se apresenta como um leque de variações do mesmo tipo de memória;

- esforçar-se para conseguir uma recomposição adequada, o que pressupõe, mais uma vez, que os pesquisadores sejam capazes, de forma neutra, de direcionar seus esforços para recompor os acontecimentos e relatá-los com o maior compromisso histórico possível, o que não ocorre sem boa dose de arbitrariedade por vários motivos: a intenção de relatar uma história empresarial específica, os tipos de documentos que se preservaram e seu conteúdo, a intenção do processo, os limites aos quais a memória se submete, a ideologia da organização etc.;

v caracterizar a continuidade e a mudança, uma vez que se pressupõe que os acontecimentos do ambiente de negócios são, em parte, continuidade, e, em parte, mudança do contexto no qual a empresa se insere em cada período histórico. Assim, a história dos negócios teria de se orientar por tais eixos, a fim de relatar como cada opção empresarial se configurou como uma resposta adequada às questões do seu tempo. É revelador que esse item nada diga sobre acasos, equívocos, fracassos e outros aspectos que compõem as trajetórias empresariais, o que sugere a construção de histórias assépticas, corretas e perfeitas, raramente compatíveis com o contexto dos negócios;

- definir a identidade da empresa, uma vez que toda história de negócios é, em maior ou menor grau, uma potencial fonte identitária. Embora os partidários da história de negócios acreditem que há características identitárias presentes ao longo das etapas da história da empresa, isso é bastante questionável. Porque a leitura da identidade é algo que pode ser feito intencionalmente, inclusive "de trás para frente" no caso de material com recorte longitudinal, sendo possível "fabricar" uma identidade organizacional do passado conforme os propósitos estratégicos do presente, por exemplo. As características que são percebidas por meio de registros históricos podem ser invenções deliberadas para salientar aspectos que hoje interessam à empresa. 
Como se percebe sem muito esforço, a história de negócios se compromete com um resgate pretensamente objetivo de um passado deliberadamente enviesado e unilateral, o que só pode ser feito com sucesso diante da ausência de contrarregistros, de materiais históricos que contem outras versões da mesma história. É desigual a competição da história que se conta com base em documentos e a história que se constitui a partir da oralidade. Mas isso não implica que essa tenha de se calar, ou se submeter àquela por conta da ausência de condições materiais de reprodução. Isso seria condenar os homens a aderir de forma sistemática a uma versão necessariamente elitista da história, o que a história nova já provou que não é o caso.

Nesse sentido, não se trata de recusar categoricamente tudo o que venha da história dos negócios, mas de reconhecer seus limites, antes de qualquer coisa, ideológicos. Não há história da dinâmica empresarial que se assente apenas sobre números e não sobre a existência concreta de sujeitos. Por isso podem ser apontadas como contribuições à abordagem:

- assumir que existe uma intencionalidade presente em qualquer tipo de registro, o que põe os documentos empresariais, por mais objetivos que pareçam, sob o mesmo tipo de suspeita que eventualmente poderia se ter sobre fontes consideradas menos objetivas. Não haveria, assim, fatos, apenas dados, que se submeteriam sempre ao escrutínio do pesquisador;

v questionar frontalmente a objetividade de informações do passado ao apontar que o registro em outra época não qualificava como neutro ou objetivo o relato, pois se trata de uma versão qualquer documento sobre qualquer assunto específico;

- destacar as possibilidades de fragmentação advindas dessa abordagem; em vez de contribuírem para uma compreensão limitada do passado, consistiriam precisamente no contrário, uma vez que, conforme Schmitt (1998:262), "por trás dessa história invertida, e ao mesmo tempo fragmentada — já que, fazendo-se pelos indícios, ela multiplica os pontos de observação - também surgem os problemas materiais e a crise de consciência da sociedade em que se escreve";

v apontar visões distintas de atores que realmente passaram pelo contexto de transformações; essa visão evidencia a desigualdade social e seus efeitos, e a responsabilidade da história de relatar as coisas com vários pontos de vista, inclusive o dos desvalidos, praticamente ignorados nas escolas históricas tradicionais. 
É preciso esclarecer que não se está prescrevendo um receituário para o mapeamento das histórias das organizações, longe disso; mas que a história empresarial é uma forma de conhecimento interessante para a análise organizacional, desde que reconhecidas suas limitações teórico-metodológicas e consideradas suas evidentes influências ideológicas. Os estudos organizacionais podem ampliar consideravelmente seu escopo ao incorporar a maneira pela qual o passado se apresenta como um processo essencialmente político. Uma agenda possível de pesquisas nesse sentido poderia abranger, por exemplo, os processos de negociação entre memórias coletivas e memórias individuais, uma vez que indivíduos e grupos sociais lembram-se do passado de maneiras distintas, e esse processo embute uma tensão política fértil para a composição de uma dada versão do passado.

O desenvolvimento de estudos sobre os tipos de memórias (oficiais, esquecidas, silenciadas, subterrâneas, clandestinas, vergonhosas, proibidas, entre outras) traz à tona as questões da legitimidade e do poder, algo que interfere inequivocamente na construção histórica. Podem ainda fazer parte da agenda dos estudos organizacionais revisões críticas de histórias já apresentadas como estabelecidas, explorando o material histórico rejeitado ou subutilizado na confecção da memória da empresa, bem como a clivagem entre memória oficial e dominante e memórias subterrâneas e a significação do silêncio sobre o passado, com foco nos fenômenos de dominação e de resistência. Ademais, avanços metodológicos podem ser buscados como meio de aprimorar a forma de lidar com o passado, controlando as distorções no ambiente empresarial.

O que lembrar e o que esquecer são questões humanas inevitavelmente complexas. No contexto organizacional, revestem-se dos agudos embates entre capital e trabalho, tornando também a história um campo de enfrentamento ideológico. Não bastassem as iniciativas de controle simbólico atualmente adotadas nas organizações, o passado se converte ele próprio também em objeto de disputa. Na ótica das empresas, quanto mais funcionalmente harmonioso for esse passado, mais isso demonstraria que são os tempos atuais os responsáveis pela crescente racionalização produtiva. Os trabalhadores, por sua vez, destituídos dos meios para construir uma história material tão articulada quanto a empresarial, limitam-se a veicular por meio da história oral outras versões dos acontecimentos, o que funciona como instância de resistência à adesão ao projeto organizacional ampliado, que procura instituir a partir do passado uma dada versão de controle. Nesse ínterim, o papel que cabe aos estudos organizacionais é procurar ampliar a compreensão da dinâmica das organizações, permitindo aos que têm voz, e pouco podem manifestá-la, que contem outras histórias. 


\section{Referências}

AMATORI, F. Business history as history. Business History, London, v. 51, n. 2, p. 143-156, Mar. 2009.

BERGER, P.L.; LUCKMANN, T. A construção social da realidade. 25. ed. Petrópolis: Vozes, 2005.

BLOCH, M. Apologia da história ou o ofício do historiador. Rio de Janeiro: Jorge Zahar, 2001.

BOOTH, C.; ROWLINSON, M. Management and organizational history: prospects. Management \& Organizational History, London, v. 1, n. 1, p. 5-30, 2006.

BURRELL, G. Ciência normal, paradigmas, metáforas, discursos e genealogia da análise. In: CLEGG, S.; HARDY, C.; NORD, W. (Org.). Handbook de estudos organizacionais. São Paulo: Atlas, 1998. v. 1.

CARRIERI, A.P.; LUZ, T.R. Paradigmas e metodologias: não existe pecado do lado de baixo do equador. In: ENCONTRO ANUAL DA ANPAD, 22., Foz do Iguaçu, 1998. Anais... Foz do Iguaçu: Anpad, 1998.

COSTA, A.M.; BARROS, D.F.; MARTINS, P.E.M. Perspectiva histórica em administração: panorama da literatura, limites e possibilidades. In: ENCONTRO ANUAL DA ANPAD, 33., Rio de Janeiro, 2009. Anais... Rio de Janeiro: Anpad, 2009.

DE DECCA, E.S. O silêncio dos vencidos. 2. ed. São Paulo: Brasiliense, 2004.

DEMO, P. Metodologia científica em ciências sociais. 3. ed. São Paulo: Atlas, 1995.

FRANÇOIS, E. A fecundidade de história oral. In: FERREIRA, M.M.; AMADO, J. (Org.). Usos e abusos da história oral. 2. ed. Rio de Janeiro: FGV, 1998.

GOURVISH, T. What can business history tell us about business performance? Competition \& Change, London, v. 10, n. 4, p. 375-392, Dec. 2006.

HARVEY, C.; WILSON, J. Redefining business history: an editorial statement. $\mathrm{Bu}$ siness History, London, v. 49, n. 1, p. 1-17, jan. 2007.

HOBSBAWM, E. Sobre história. São Paulo: Companhia das Letras, 2007.

JANOTTI, M.L. O livro fontes históricas como fonte. In: PINSKY, C.B. (Org.) Fontes históricas. São Paulo: Contexto, 2006.

LE GOFF, J. A história nova. 4. ed. Rio de Janeiro: Martins Fontes, 1998.

LE GOFF, J. História e memória. Campinas: Unicamp, 1992. 
LE GOFF, J. Memória/história. In: Enciclopédia Einaudi. Porto: Imprensa Nacional/ Casa da Moeda, 1984. v. 1.

LEBLEBICI, H.; SHAH, N. The birth, transformation and regeneration of business incubators as new organizational forms: understanding the interplay between organizational history and organizational theory. Business History, London, v. 46, n. 3, p. 353-380, July 2004.

LEFEBVRE, G. O nascimento da moderna historiografia. Lisboa: Sá da Costa, 1981.

LOBO, E. História empresarial. In: CARDOSO, C.F.; VAINFAS, R. (Org.). Domínios da história: ensaios sobre teoria e metodologia. Rio de Janeiro: Elsevier, 1997.

MAIELLI, G. History under cover: the problematic relationship between business management and the past. Competition \& Change, London, v. 10, n. 4, p. 341-356, Dec. 2006.

MARTIN, J. Cultures in organizations: three perspectives. London: Oxford University Press, 1992.

PAGÈS, M. et al. O poder das organizações. São Paulo: Atlas, 1987.

POLLAK, M. Memória e identidade social. Estudos Históricos, Rio de Janeiro, v. 5, n. 10, p. 200-212, 1992.

POLLAK, M. Memória, esquecimento, silêncio. Estudos Históricos, Rio de Janeiro, v. 2, n. 3, p. 3-15, 1989.

REED, M. Teorização organizacional: um campo historicamente contestado. In: CLEGG, S.; HARDY, C.; NORD, W. (Org.). Handbook de estudos organizacionais. São Paulo: Atlas, 1998. v. 1.

RICOEUR, P. A memória, a história e o esquecimento. Campinas: Unicamp, 2007.

ROWLINSON, M. et al. Social remembering and organizational memory. Organization Studies, Berlin, v. 31, n. 1, p. 69-87, Jan. 2010.

SCHMITT, J.-C. A história dos marginais. In: LE GOFF, J. (Dir.). A história nova. 4. ed. Rio de Janeiro: Martins Fontes, 1998.

SCHWARCZ, L.M. Prefácio. In: BLOCH, M. Apologia da história ou o ofício do historiador. Rio de Janeiro: Jorge Zahar, 2001.

WALSH, J.P.; UNGSON, G.R. Organizational memory. The Academy of Management Review, Briarcliff Manor, v. 16, n. 1, p. 57-91, Jan. 1991. 